\title{
Getting a Quality Education: Indigenising Post-Secondary Institutions in Northern Ontario Through the Indigenous Quality Assurance Project
}

\section{INTRODUCTION}

For half a century, Canadian institutions have recognised the need to improve Indigenous peoples' participation in higher education. ${ }^{1}$ The concept of indigenisation has emerged from these earlier conversations and various commitments toward indigenisation have been made. In Ontario, Canada, the Ministry of Training, Colleges and Universities' (MTCU) Aboriginal Post-secondary Education and Training Policy Framework ${ }^{2}$ has acknowledged Indigenous worldviews and cultures and affirmed the place of Indigenous knowledge systems in the development and delivery of postsecondary education and training programmes, services, curriculum and evaluation mechanisms. Many institutions have signed onto Indigenous education manifestos such as College and Institutes Canada's Indigenous Education Protocol and Universities Canada's Principles on Indigenous Education which advocates for the respectful inclusion of Indigenous knowledge systems in western systems of education, and the meaningful participation and representation of Indigenous peoples in the academy.

Despite the public calls and affirmations of many post-secondary institutions to Indigenous education, there has been an under-examination of the culture of the schools themselves to see what counts as knowledge and truth and what does not. Questions arise about the genuine willingness of post-secondary institutions to embrace Indigenous peoples and their knowledge systems in their totality. ${ }^{3}$ Many Indigenous scholars are wary that attempts of indigenisation can never be more than superficial, because 'doing it right' would undoubtedly rattle colonial structures and projects which seem fit to remain firmly entrenched in the fabric of Canadian society. ${ }^{4}$ Instead, indigenisation in its current state has been seen as another 'spectacle of reconciliation,' which situates Indigenous suffering alongside white settler remorse for the purposes of legitimising and securing settler futurity. ${ }^{5}$ 
While indigenisation is commonly referred to in the academy and has even been aligned with the Truth and Reconciliation Commission of Canada on the Indian Residential School System, ${ }^{6}$ there is a lack of consensus on what indigenisation means and how it can be achieved among colleges and universities. ${ }^{78}$ Gaudry and Lorenz ${ }^{9}$ put forth that there are three competing notions of what constitutes indigenisation: Indigenous inclusion, reconciling indigenisation, and decolonial indigenisation. Whereas inclusion refers to a process whereby presence is increased and supports are offered to Indigenous students, faculty and staff to acclimatise them to the current culture, reconciliation and decolonial forms of indigenisation promote system transformation to varying degrees. ${ }^{10}$ Among post-secondary institution leadership, this term has predominately meant increasing the presence of Indigenous faculty and staff, and the student complement. ${ }^{11}$ Yet what is resoundingly clear among Indigenous scholars is that indigenisation must be about transformational change. It must create meaningful space for Indigenous peoples and their knowledge systems within institutional structures, academic disciplines, policies and practices. ${ }^{12}$ It must challenge "structures of dominance" ${ }^{13}$ and it must have Indigenous peoples at its forefront. ${ }^{14}$

In an effort to engage in indigenisation in a manner consistent with the calls of Indigenous scholars, six colleges in Northern Ontario, Canada: Cambrian College, Canadore College, Collège Boréal, Confederation College, Sault College, and Northern College (herein referred to as 'the northern colleges') undertook the Indigenous quality assurance (IQA) project. The northern colleges are situated upon the traditional territories of the Anishinaabe and Mushkegowuk nations, and areas where there is a historical Métis presence. On average, 15 percent of the northern student population are Indigenous. ${ }^{15}$

Skolnik refers to quality assurance as "the monitoring, evaluation or review of higher education in order to establish stakeholder confidence that it fulfils expectations or meets minimum requirements." 16 The IQA project's main objective was to design and implement an Indigenous quality assurance system. The project sought to do this by: understanding the meaning of quality assurance from the perspective of Indigenous peoples in Northern Ontario; creating a set of Indigenous quality assurance standards that are reflective of the peoples and cultures of Northern Ontario; creating and implementing an Indigenous quality assurance process to support implementation, reporting and accountability in relation to the Indigenous quality assurance standards; and, employing an action-based research methodology to conduct research with Indigenous peoples.

This paper will provide an overview of the northern colleges' IQA system and explore how the northern colleges' Indigenous quality assurance system can provide a tangible path forward to enact indigenisation. In particular, the capacity of Indigenous quality assurance to address the calls by Indigenous scholars to ensure indigenisation efforts are systemic, led by Indigenous peoples, but inclusive of the entire post-secondary institution, and accountable to Indigenous peoples are discussed.

\section{QUALITY ASSURANCE IN ONTARIO}

In Ontario, colleges must undergo a quality assurance audit process that is led by the Ontario College Quality Assurance Service (OCQAS), which is an independently operated oversight and governance body that is owned, operated and funded by the 24 public colleges in Ontario. ${ }^{17}$ The 
primary responsibilities of OCQAS are to ensure that Ontario colleges conform to the MTCU'S Credential Framework, and to lead the audit process which is used to assess the effectiveness of quality assurance systems at colleges in Ontario. ${ }^{18}$ Currently, it is mandatory for all colleges in Ontario to participate in the audit process. Ontario colleges must undergo a review every five years and are required to submit an activity/progress report 18 months after the formal board approval of the final audit report.

The college quality assurance audit process (CQAAP) establishes if institutional systems are functioning properly through an examination of programme-level evidence. The focus of CQAAP is on the presence and effectiveness of quality assurance mechanisms and not about ensuring a certain set of quality assurance mechanisms are in place. This allows an institution to implement a set of quality assurance mechanisms that are reflective of their priorities. ${ }^{19}$ While a variety of mechanisms (for example, policies, committees, guides) can be used in a quality assurance process, the audit portion is based on the following agreed upon and predetermined standards: (1) programme quality management system; (2) programme development; (3) conformity with government requirements; (4) programme delivery and student assessment; (5) existence, monitoring and communication of academic policies and practices; and, (6) availability and allocation of college-wide resources. Institutions must demonstrate the implementation, effectiveness and review of their mechanisms to meet these standards. The effectiveness of these mechanisms is assessed on their ability to achieve stated objectives, identify areas of strength and areas for improvement, and implement corrective measures for improvement.

\section{INDIGENOUS QUALITY ASSURANCE}

Indigenous quality assurance systems are being implemented around the globe, including in Ontario, Canada to varying degrees. The most common approach has been the creation of a locally defined set of guidelines, principles and/or values that reflect the cultural essence to which the goals of an institution are directed and under which it operates. ${ }^{20}$ Commonly referred to as cultural standards (but referred to as IQA standards in the IQA project) these standards are used to assess the cultural integrity of the institution. For example, the Nā Lau Lama (A Statewide Collaboration to Improve Outcomes for Hawaiian Students) has developed a set of standards to help guide the process of culturally relevant assessment, ${ }^{21}$ and the Alaska Native Knowledge Network has created a set of cultural standards which are used to ensure programmes are meeting local standards and are culturally grounded, but are also influencing district and state wide goals. The standards:

...serve as a complement to, not as a replacement for, those adopted by the State of Alaska. While the state standards stipulate what students should know and be able to do, the "Cultural Standards" are oriented more toward providing guidance on how to get them there in such a way that they become responsible, capable and whole human beings in the process. The emphasis is on fostering a strong connection between what students' experience in school and their lives out of school by providing opportunities for students to engage in in-depth experiential learning in real-world contexts. ${ }^{22}$

Indigenous accreditation boards exist nationally and internationally, and require institutions to have a set of cultural or Indigenous quality assurance standards. The World Indigenous Nations Higher Education Consortium (WINHEC) has created an Indigenous accreditation body for Indigenous 
institutions and Indigenous programming in both Indigenous and mainstream institutions. ${ }^{23}$ While the accreditation process does give consideration to linkages with external accreditation systems, the primary focus of the audit is the institution/programme's internal congruence and cultural integrity as it relates to three broad standards: language, culture and spiritual beliefs. ${ }^{24}$ To ensure validity in this review process, there must be significant participation by Indigenous peoples served by the institution/programme, including local Elders and cultural practitioners, in the establishment of review criteria, self-study, and review process. The process must also be mindful of the importance of language. ${ }^{25}$

At least 15 institutions have been fully accredited including three Indigenous-led Ontario-based institutions: Seven Generations Institute, First Nations Technical Institute, and Shingwauk Kinoomaage Gamig. To date, no colleges in Ontario have been fully accredited through this process. Upon accreditation, institutions become a full member of the consortium and are able to develop standards and procedures. ${ }^{26}$ As an alternative to full accreditation, institutions may also be granted affirmation or affiliation status, indicating that they demonstrate commitment to recognised principles of cultural integrity and educational benefit on behalf of the Indigenous people being served, or that they are formally engaged with an accredited institution, respectively. ${ }^{27}$ Canadian specific, the National Indigenous Accreditation Board (NIAB) was developed in 1995 at a national post-secondary meeting held in Alberta. Among its founding members are Yellow Quill College and Blue Quills First Nations College. ${ }^{28}$ The purpose of the NIAB is to create an Indigenous mechanism and process to accredit and certify Indigenous programmes and institutions that meet the standards collectively identified by NIAB members. This is achieved through the assessment of an institution/programme in terms of its achievements, congruence to stated goals and objectives, and confirmation of cultural relevancy and accountability to the Indigenous nation and peoples that it serves. ${ }^{29}$

The primary focus of the NIAB's audit is the institution/programme's internal congruence and cultural integrity, which is presented through the institution's/programme's cultural standards. Through accreditation, the NIAB seeks to confirm the achievements of the institution in ten educational and administrative areas, uncover strengths and weaknesses through self-study, act upon that knowledge, encourage the institution to improve the quality of its instruction and administration, and encourage the institution to continue to work toward higher levels of excellence. To ensure validity in this review process, Indigenous peoples served by the institution/programme, including local Elders and cultural practitioners, actively participate in a culturally relevant review process. ${ }^{30}$

\section{INDIGENOUS THOUGHT, QUALITY ASSURANCE AND POST-SECONDARY EDUCATION}

Skolnik argues that the development and implementation of quality assurance can be a highly technocratic procedure, presenting as 'culture-neutral' while ignoring potential power imbalances. ${ }^{31}$ Indigenous scholars such as Meyer take issue with the culture-neutral claims of quality assurance, explaining that from an Indigenous perspective, quality assurance is not about templates, comparisons, or aggregated data but rather about understanding how language, culture, and belief systems are strengthened through coursework and community participation. ${ }^{32}$ She goes on to attest that quality is present when local cultures that are rooted to place, clarify how they wish to be seen. ${ }^{33}$ 
The theme of quality assurance as culture-neutral was also problematised in the IQA project. An initial step of the project was for the Principal Investigator to conduct a comprehensive review of quality assurance at the northern colleges over the course of the last programme cycle. The review found auditor reports from a number of Ontario colleges included statements which made quality judgements about Indigenous education at the northern colleges. For example, colleges were commended for their cultural competency training, embedding cultural competencies through courses, the delivery of quality education to Indigenous students in their area and beyond, partnerships and relationships with Indigenous communities and knowledge holders. ${ }^{34} 35$ It is unknown if any of the auditors who made statements about the quality of Indigenous education are Indigenous or how they had engaged with Indigenous peoples to come to these conclusions. Moreover, it was unknown what mechanisms and evidence informed these statements and how the auditors came to such conclusions. This reaffirmed the project's function to create a system in which Indigenous peoples could define quality.

Quality must be evaluated "in terms of the purposes the institution seeks to accomplish" ${ }^{36}$ and because quality assurance is concerned with the purpose of fit, tensions can arise in assessing quality when post-secondary institutions articulate a different vision of Indigenous education. From Indigenous perspectives, education is seen as a holistic and life long process that supports intellectual, spiritual, emotional and mental growth and development, and the ability to engage in ethical relationships with the rest of the world. For example, Longboat insists that education be founded on values such as environmental stewardship, altruism and resiliency, so that it may lead to self-determination; address inequalities and poverty; support diversity and increase sustainability. ${ }^{37}$ Within this understanding of education, "quality assurance in education mean[s] the reproduction of . . . languages, culture and social usages." 38 Jacob and colleagues agree, stating that compared to non-Indigenous-based accreditation bodies, WINHEC's process is unique because of its focus on Indigenous values, cultures, and languages. ${ }^{39}$ Meanwhile, various scholars have noted that due to increased financial pressures, post-secondary institutions are more than ever aligning themselves with market and employment priorities and engaging in industry collaborations. ${ }^{4041}$

Historical methods to evaluate success, such as the commonly employed key performance indicators in the Ontario college system, which report on graduate employment rate at six months after graduation, graduate satisfaction rate, employer satisfaction rate, student satisfaction rate and graduation rate, may not be an appropriate mechanism to evaluate quality within an Indigenous quality assurance process as "performance indicators are only relevant in the context in which they were set." 42 Besken illustrates this point by arguing that graduation rates do not fit a student body with goals to transfer to four-year colleges, to acquire remedial assistance or learn for personal curiosity or growth. ${ }^{43}$ Zepke and Leach provide further comment, relaying that integration and the adaptability of institutions are better indicators of quality than retention. ${ }^{44}$

Paquette and Fallon describe Indigenous education as a 'parity paradox,' explaining that it must fulfill two purposes seemingly at odds: deliver culturally grounded education and adhere to Western notions of quality in education. Yet the two notions of education do not have to be mutually exclusive. Wabano argues that Indigenous programmes within mainstream postsecondary institutions are 'programmes plus' because they are held accountable to the same quality standards as mainstream programmes plus are expected to be responsive and accountable to Indigenous communities: 
Given the often experiential and wholistic nature of learning occurring in these programs, evidence of this learning to demonstrate rigour must be well thought out. Additionally, recognition and assessment of bi-cultural approaches being taught in Indigenous programs must also be demonstrated. This requires a different approach to evaluating and assessing program quality for Indigenous programs. A review that takes into consideration the vastly different approaches found within Indigenous programs would articulate that Indigenous-based programs are in fact Ontario college programs plus. Such programs are enhanced programs that prepare its graduates for practice within mainstream systems and with Indigenous populations who have very unique and special circumstances. ${ }^{45}$

This work, facilitated predominately by Indigenous peoples, faculties, and departments remains hidden work in institutions yet through Indigenous quality assurance there is an opportunity for this work to be a mechanism to improve quality of education and function across the institution.

\section{METHODOLOGY}

Indigenous Participatory Action Research (IPAR) and Institutional Ethnography (IE) served as the framework of inquiry for the project. The approaches were seen as complementary as the project included both the production of culturally relevant knowledge (served by IPAR) and the deconstruction of knowledge (served by IE). As Sinclair notes, IPAR provides a space for holistic knowledge and Indigenous voice as it allows participants, particularly from marginalised groups, to analyse and define their own solutions to problems that they may face. ${ }^{46}$ Through IPAR, Indigenous knowledge holders and Indigenous ways of knowing were central to the development of the IQA standards.

IE provides space for deconstruction as it provides a means to examine power relations and world assumptions within institutional operational documents, through a multitude of methods including open ended discussions, analysis of secondary documents and mapping. ${ }^{47}$ It "problematizes social relations at the local site of lived experience, while examining how sequences of texts coordinate actions, consciousness, and forms of local organization." 48 In the IQA project, IE was used critically to examine and question the universality of quality assurance at northern colleges and, through institutional mapping activities, world assumptions and power relations within the current quality assurance system became visible, allowing for the envisioning of alternatives.

The Indigenous quality assurance project consisted of three main activities: sharing circles among Indigenous knowledge holders, quality assurance leads and Indigenous education leads from each northern college; site visits and institutional mapping with the colleges; and a pilot of the IQA system.

\section{Sharing Circles}

Indigenous leads, knowledge holders and quality assurance leads from the northern colleges participated in three two-day gatherings which took place in August 2016, November 2016 and February 2017 to develop the Indigenous quality assurance standards. Over the six-day period, those in attendance participated in ceremony and discussions. Central questions posed at the first two gatherings were: How do you envision education? And, what does it look like when we are doing it right? The voices of the knowledge holders were privileged during these sessions and their vision of and experience in Indigenous education was foundational to the development of the standards. 
After each gathering, the principal researcher compiled ideas, concepts, and concerns to draft and subsequently revise the standards. A series of teleconferences and an additional meeting were also carried out to review and revise the standards. The draft standards were also presented and discussed during the college site visits (discussed below), further informing their development. It was these subsequent activities that supported a more granular understanding of the standards.

\section{College Site Visits and Institutional Mapping}

To garner broader engagement in the development of the Indigenous quality assurance standards and to inform the development of the Indigenous quality assurance process, site visits to five of the six northern colleges was conducted between February-March 2017 and their duration ranged from one-half to two days. The main objective of the site visits was to explore current mechanisms of indigenisation and possibilities through interactive process mapping activities which documented current and future IQA processes and standards. In total, 29 college employees, seven Indigenous community members and three Indigenous students participated in these sessions.

\section{Indigenous Quality Assurance System Pilot}

To test the Indigenous quality assurance system that was developed, Canadore College and Collège Boréal participated in a self-study between April-May 2018. Canadore College underwent a full self-study of their institution and Collège Boréal undertook a segment of the self-study, focusing on their support services. Additionally, to test different process options, Canadore College aligned their self-study process with the CQAAP self-study data collection process and Collège Boréal embarked on a stand-alone self-study. The self-study findings were presented to Indigenous knowledge holders, Indigenous leads and quality assurance leads from the other northern colleges, who then had an opportunity to ask questions and seek clarification on the self-study. This process was implemented to simulate aspects of a fulsome audit.

\section{RESULTS}

This section outlines the Indigenous quality assurance system that was created through the Indigenous quality assurance project. It is outside the scope of this paper to present the implementation process in detail but this section does present Indigenous concepts of quality assurance, the Indigenous quality assurance standards and the principled framework that guides implementation.

\section{'Weweni': An Indigenous Concept of Quality}

Through the Indigenous quality assurance project, Indigenous knowledge holders from across northern Ontario conceptualised quality assurance as 'weweni'. In the Anishinaabe language, the word 'weweni' embodies the concepts of 'that good way,' and 'looking after something properly.' Achieving 'weweni' means building a learning system that is reflective of the worldviews, cultures, educational needs and aspirations of local Anishinaabe, Mushkegowuk and Métis communities. It is ultimately about looking after something (education at the colleges) to ensure that we are looking after someone (the emotional, physical, mental and spiritual well-being of Indigenous and non-Indigenous peoples).

'Weweni' is a holistic model for quality assurance that can be achieved when post- secondary institutions, with the guidance of Indigenous peoples work to ensure that appropriate and 
respectful mechanisms (for example, structures, policies, practices, processes, programmes, guides, plans, committees) at an institutional level (college-wide areas and functions) and at a programme level (academic programmes, support services and community relationships) are in place to meet the vision communicated in and through the Indigenous quality assurance standards. A visual representation of this understanding is found in Figure 1.

\section{The Indigenous Quality Assurance Standards}

The vision of the IQA system is to build a college learning system that is reflective of the worldviews, cultures, educational needs and aspirations of local Anishinaabe, Métis

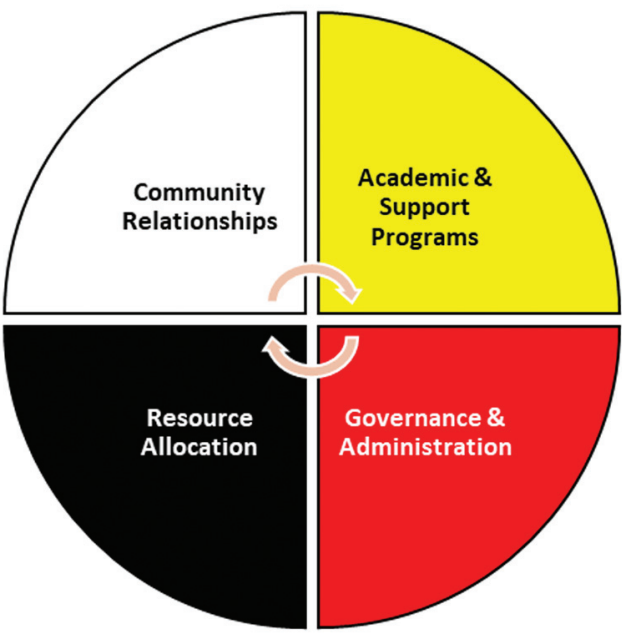

Figure 1. An Indigenous Quality Assurance Model and Mushkegowuk communities to support the emotional, physical, mental and spiritual well-being of Indigenous and non-Indigenous peoples. This is accomplished through four Indigenous quality assurance standards:

1. Celebration and Sharing: Indigenous ways of knowing and doing are celebrated as invaluable to the entire college community and shared openly in well informed and culturally based ways.

2. Honour and Respect: Indigenous peoples are respected as collective authorities on their knowledge systems and are honoured through active participation in key college activities.

3. Place and Purpose: The college is reflective and supportive of Indigenous learners and their experiences, and helps prepare them for mino-bimaadiziwin, to live a good life of treating oneself, other people, and the land with respect and kindness.

4. Relationship with Land: The college community acknowledges Indigenous peoples' relationship to land, with earth as their mother, and develops its own close connection with the land, supporting efforts of reconciliation and peace.

The standards are not prescriptive but instead ensure that the mechanisms put in place to ensure quality are adequate and culturally-responsive. Each standard has a set of seven affiliated requirements which identify expectations at a programme and/or institutional level. A rubric was also created for each standard, with each requirement having a corresponding row in the rubric. The rubrics were fashioned in the colors of the medicine wheel to represent a non-linear process in quality improvement. The medicine wheel is a symbol familiar to and used by various Indigenous nations across North America to convey a complex holistic paradigm. In addition to the rubrics providing guidance in the interpretation of the standards, the rubrics also illustrate improvement in quality, as colleges move through the phases of the medicine wheel: see, relate, understand, and act. 
The resource guide, Building a Strong Fire: Indigenous Quality Assurance Standards in Ontario Colleges, outlines the standards in more detail, and includes the requirements and rubrics. The document can be accessed at Canadore College's Indigenous Quality Assurance webpage: https:// www.canadorecollege.ca/corporate/indigenous-education/indigenous-quality-assurance.

\section{The Indigenous Quality Assurance Framework}

To implement the Indigenous Quality Assurance Standards, a process was developed that is independent from, but aligned with, the OCQAS provincial audit process. While it is beyond the scope of the paper to discuss the step by step audit process, the following principles and goals guide its implementation.

An Indigenous quality assurance system must:

- be founded upon the knowledge systems of local Indigenous peoples through a set of locally developed Indigenous quality assurance standards;

- be consistent with and respectful of local Indigenous practices and protocols;

- meaningfully include Indigenous peoples throughout the process;

- be effective, efficient, and cyclical;

- operate as a self-evaluation of each college's institutional mechanisms, including processes and policies;

- document the self-evaluation through a self-study;

- use a culturally competent, objective peer review panel;

- follow a mandatory and clear process that identifies strengths and weaknesses, recommends improvements, and facilitates positive change;

- distribute the preliminary report to the college for their response and include the college response in the final report; and,

- distribute the draft final report to the college's Indigenous education council or equivalent for review and approval;

When it seeks to:

- Assess the extent to which the college is meeting the Indigenous Quality Assurance Standards;

- Stimulate the institution to discover its strengths and gaps in relation to Indigenous education through self-study, and to act upon that knowledge;

- Encourage the institution to improve the quality of its instruction, administration and relationships with Indigenous peoples;

- Encourage the institution to continue to work toward higher levels of excellence in Indigenous education; and,

- Affirm the right of Indigenous peoples to have access to educational programs founded on Indigenous values and knowledges. 


\section{INDIGENOUS QUALITY ASSURANCE AND INDIGENISATION}

This section explores how the northern colleges' Indigenous quality assurance system can provide a tangible way forward to enact indigenisation. Salient themes found within the indigenisation literature are used to guide this discussion. Specifically, this section demonstrates how the Indigenous quality assurance standards and the overall implementation of an Indigenous quality assurance system supports a framework for indigenisation that is: systemic, led by Indigenous peoples, yet everyone's responsibility in the academy, and is accountable to Indigenous peoples.

\section{System Transformation}

To move higher education beyond 'inclusion indigenisation' to 'reconciliation indigenisation,' those within the walls of the institution must change the way they think about and act towards Indigenous peoples and their knowledge systems. ${ }^{49} \mathrm{~A}$ process that considers indigenisation in the context of quality assurance can facilitate a shift in the institution.

In many cases, Indigenous education remains an afterthought or is superficial at best. Commitments are mostly principled, but lack an adequately funded implementation plan and, when implemented, are predominately resourced through special project funding and not by core institutional funding. For example, Daigle discusses how a university-based centre to support ongoing research and dialogue about Indian Residential schools (IRS) and reconciliation recieved an extravegant soft opening, yet almost a year later the Centre was reported to have lost IRS records, was understaffed and underfunded, and not yet formally opened. ${ }^{50}$ The Centre director insisted that this was indicative of the Centre being positioned as a trophy instead of a serious and impactful place. ${ }^{51}$

Quality assurance provides an avenue for indigenisation efforts to become integral to the fitness of the institution and counters the discourse of indigenisation as something that is an add-on and/or "nice to have." This repositioning of indigenisation from a 'special project,' or 'trophy' to a function of quality has significant implications. For one, a robust quality assurance system includes a demonstration by institutions that adequate resources are in place to support proper implementation. Akin to other quality assurance procesess, the Indigenous quality assurance system includes a requirement for the adequate resourcing of Indigenous education and initiatives. As the process is Indigenous led, it ensures that what is adequate is defined by and informed by Indigenous peoples. In the above example, there would have to be a demonstration and reporting of adequate financial and human resources and an explanation of why the Centre was not yet open. Additionally the quality assurance audit could include a discussion with the Centre Director during the site visit, especially if this was flagged as an issue by the Indigenous auditors when reviewing the self-study. Moreover, the institution would then describe how it intends to meet its stated objectives for the Centre over a multi-year plan.

Pidgeon's position that incorporating Indigenous knowledges into the academy must be multifaceted, relationship-based and facilitated through relevant policies, programmes, and services, ${ }^{52}$ is also supported by the Indigenous quality assurance system. As established in Figure 1, the Indigenous quality assurance system is holistic and expansive. It is inclusive of all facets of the college, including academic programming, governance and administration, student supports, community relationships and resource allocation, in an effort to ensure quality education. 
The standards are also relational and facilitate relational thinking in the academy. For example, if a college has implemented Standard 1: Requirement 1, 'Learners are provided with an opportunity to learn about Indigenous peoples, cultures, and histories' and Standard 1: Requirement 4, 'Learners experience through Indigenous ways of knowing and doing' yet is unable to provide evidence to demonstrate Standard 1: Requirement 5, 'Elders in Residence and/or other Indigenous knowledge holders play an integral role in the delivery of Indigenous knowledges' and Standard 2: Requirement 6 , 'Indigenous peoples are meaningfully involved in the development, delivery and management of Indigenous education,' this raises flags about the quality of such academic programming.

\section{Everyone's Responsibility, Yet Indigenous Led}

Indigenous faculty and departments have borne the brunt of the responsibility to implement indigenisation efforts and change the institution. ${ }^{53}$ This work is emotional, time consuming, and can also include mitigating white guilt and settler fragility. ${ }^{54}$ In addition to being a daunting task, indigenisation is often an impossible one as Indigenous peoples must influence systems change across the institution for meaningful indigenisation to occur, ${ }^{55}$ yet, rarely are they in positions of power, adequately staffed or well-resourced. By situating indigenisation within quality assurance, the responsibility is dispersed across the institution. For example, there is a role to play for adminstration and leadership in terms of financial and human resources, Indigenous community engagement, and governance.

While the responsiblity is shared, through the principles of the IQA framework and the Indigenous quality assurance standards, ensuring indigenisation is Indigneous-led also becomes a measure of quality. Aside from quality assurance standards being designed collaboratively with Indigenous knowledge holders from the territories in which the colleges reside, the IQA system also strengthens the ongoing role of Elders and Indigenous knowledge holders in higher education. The IQA process ensures that Elders and/or Indigenous knowledge holders are involved in the ongoing assessment of quality as advisors during the self-study, and by participating in the auditor site visit. The process also recommends that an Elder or someone who possesses cultural knowledge be included as an auditor.

The value and necessity of including Elders or Indigenous knowledge holders was apparent in the pilot site audit. The presence of the knowledge holders during the self-study presentations supported further local contextualisation of the standards. For example, in regards to Standard 3: Requirement 1, 'physical spaces and events are reflective of Indigenous cultures and peoples,' one of the colleges shared that there were various Indigenous items and visual representations in the college. One of the knowledge holders asked what was being done to ensure that the college community was knowledgeable about the meaning and significance of the items, and what steps were being taken to ensure that they were being properly cared for. This conversation resulted in a recommendation that all college employees receive training on the importance and significance of such items.

In regards to the same standard requirement, a college shared infromation about a pow wow they were planning as a form of evidence for the standard requirement. Knowledge holders questioned the appropriateness of the pow wow in this specific context. They shared the history and purpose of the pow wow and explained that such an event was not practiced by all Indigenous peoples. They 
also shared that when it was appropriate for a pow wow to be held at the college it needed to be Indigenous-led. In both of these cases, the participation of the knowledge holders ensured that the assessment of quality moved past what Pidgeon describes as a 'check-the-box' approach and was derived instead from complex and localised context. ${ }^{56}$

\section{Accountability}

Pidgeon calls for post-secondary institutions to include mechanisms to demonstrate accountability in regard to their indigenisation efforts. ${ }^{57}$ Central to the Ontario quality assurance audit process and the Indigenous quality assurance system is evidence that mechanisms are in place. While quality assurance does not dictate what mechanisms are to be in place, evidence of their effectiveness must also be demonstrated.

An area of indigenisation that has been heavily scrutinised is the appointment of Indigenous peoples to advisory or governing boards, and Indigenous advisory boards. Pidgeon notes that Indigenous advisory committees can be underused and serve solely as an institutional window dressing with limited power to make change. ${ }^{58}$ The Indigenous quality assurance system works to strengthen the role of Indigenous Education Councils at colleges. In addition to a number of Indigenous quality assurance standard requirements which call for Indigenous peoples to occupy decision-making and leadership positions throughout the college, the Indigenous quality assurance process provides a mechanism for meaningful engagement with the college's Indigenous Education Council. The IQA system requires the Indigenous Education Council or a similar Indigenous-controlled body to review and approve the auditor report and follow-up monitoring reports. The Indigenous quality assurance standards also provides a tool to facilitate collaborative planning and goal setting between the college and its Indigenous Education Council.

Indigenous-defined quality standards work to move past superficial understandings of reconciliation and indigenisation as institutional mechanisms, and evidence on key functions of quality are defined by Indigenous peoples for Indigenous peoples. Institutions have largely addressed reconciliation through culture and feel-good initatives, and have evaded conversations and actions that are uncomfortable, unpopular and less lucrative (at least from a short-term and narrow lens). For real change to occur, institutions must acknowlege that colonial violence is broader than historical Indian residential schools, and is ongoing. ${ }^{59}$ They must also take up actions to stop the colonial violence that continues to subjugate Indigenous lands and peoples. ${ }^{60}$ For example

Standard 4, 'Relationship to Land' includes requirements for institutions to educate the college community about the lands in which they occupy, local Indigenous peoples cultures and histories, examine how their academic and institutional practices currently impact Indigenous peoples, and make efforts to ensure Indigenous learners maintain their connections to their homelands and communities while attending college.

\section{FINAL REFLECTIONS}

Battiste asserts that to decolonise our education systems we must "understand the distinction between the outer structures of education-programs, policies, and practices-and the inner consciousness of Indigenous knowledge." She explains that change will occur only if we are willing to first do the inner work and engage directly with Indigenous knowledge and consciousness. ${ }^{61}$ While the Indigenous quality assurance project sought to develop and implement a quality assurance 
system that can impact outer strategies, the work was derived from Indigenous knowledge and consciousness. Through an Indigenous participatory action approach, Indigenous knowledge holders were at the forefront of the project. Their guidance ensured that Indigenous concepts of education remained the focus and their efforts culminated in the birthing of a set of Indigenous quality assurance standards.

The Indigenous quality assurance system provides a framework for Indigenous peoples and knowledge systems to occupy higher education in a respectful and culturally-based, yet nonprescriptive manner, while critically exploring an institution's role as active agents of settler colonialism. Indigenous quality assurance begins from an Indigenously defined place and continues to create a space for an ongoing (re)negotiation of power, place, identity and sovereignty. ${ }^{62}$ Through the Indigenous quality assurance system's assertion that quality in Indigenous education begins with the presence and direction of Indigenous peoples, colleges who adopt the framework can move toward embracing Indigenous peoples and knowledge systems in their totality. ${ }^{63}$

While the Indigenous quality assurance system is only in its infancy, we have glimpsed its potential. During the self-study presentations, it was remarked that the Indigenous quality assurance process forces people to think differently about quality and that the standards were a tool that facilitated the college to reflect and think holistically about how they do things.

The system has also helped institutions challenge their own narratives of what they are doing to progress indigenisation. In some instances, the pilot sites had not done anything to satisfy requirements of the standard, and in many cases colleges identified that while there were actions taken to satisfy requirements, they were informal and there were not sufficient mechanisms and evidence in place to demonstrate adequately their implementation of the standard. Those who participated in the self-study presentation and question period believed that the relationship between the standards, and mechanisms and evidence was two-sided, and that having a formalised Indigenous quality assurance system will drive the development of mechanisms and evidence. The self-study also helped to clear up misnomers of what the institutions thought they were doing. In one instance there was an assumption that there was a mandated Indigenous seat on the college's Board of Governors, when in reality there was an Indigenous person who held a seat but was not there in the official capacity as an Indigenous representative.

Overall, both of the college pilot sites stated that the Indigenous quality assurance system served its function of promoting continuous quality improvement. Both colleges identified and committed to steps to improve quality further as understood through an Indigenous lens at their institution, including the college from the above example, now pursuing a reserved seat for an Indigenous representative on their Board of Governors. In her seminal article, "More than a checklist: Meaningful Indigenous inclusion in higher education," Michelle Pidgeon asked what an indigenised institution looks like. While we do not claim to have all the answers, we believe that an Indigenous quality assurance system may provide part of the soluton. ${ }^{64}$ 
Dr. Lana Ray (Anishinaabe from Opwaaganasiniing) is an Assistant Professor in the Department of Indigenous Learning at Lakehead University. Her research interests include Indigenous research methodology and storytelling, Indigenization and land-based learning. Her work seeks to advance Indigenous social, cultural and political realities through resurgent and decolonial praxis.

Mary Wabano, MSW, (Attawapiskat First Nation) is the Director of the First Peoples' Centre and Associate Dean of the School of Indigenous Studies at Canadore College. She oversees culturally appropriate student services, program quality and assurance, curriculum development, program design and community partnerships and research involving Indigenous peoples at the college.

Deidre Bannerman is the Academic Director of Quality Learning, Teaching and Innovation at Canadore College where she provides leadership for program quality assurance, curriculum integrity, professional development related to teaching and learning, applied research, academic policy review and revision, and special projects and initiatives.

1. Michelle Pidgeon, "More Than a Checklist: Meaningful Indigenous Inclusion in Higher Education," Social Inclusion, 4:1 (2016), 77-91.

2. Ministry of Training, Colleges, and Universities (MTCU), Aboriginal Postsecondary Education and Training Policy Framework (Toronto: MTCU, 2011).

3. Jo-Ann Episkenew, "Indigenizing university administration or Tâwaw cî? (Take 2)," in Transforming the Academy: Essays on Indigenous Education, Knowledges and Relations, ed. Malinda Smith (Edmonton: University of Alberta, 2013), 6468.

4. Pidgeon, "More Than a Checklist."

5. Michelle Daigle, "The Spectacle of Reconciliation: On (the) Unsettling Responsibilities to Indigenous Peoples in the Academy," Environment and Planning D: Society and Space, 37:4 (2019), 703721, 4.

6. Elizabeth Brulé, and Ruth Koleszar-Green, “Cedar, Tea and Stories: Two Indigenous Women Scholars Talk About Indigenizing the Academy," Cultural and Pedagogical Inquiry, 10:2 (2018), 109-118.

7. Ibid.

8. Adam Gaudry, and Danielle Lorenz, "Indigenization as Inclusion, Reconciliation, and Decolonization: Navigating the Different Visions for Indigenizing the Canadian Academy," AlterNative, 14:3 (2018), 218 -227, https://doi. org/10.1177/1177180118785382

9. Ibid.

10. Ibid, 218-19.

11. Ibid, 218.

12. Pidgeon, "More Than a Checklist."

13. Brulé and Koleszar-Green, "Cedar, Tea and Stories," 11.

14. Gaudry and Lorenz, "Indigenization as Inclusion, Reconciliation, and Decolonization."
15. Colleges Ontario, Student and Graduate Profiles18: Environmental Scan 2018 (Toronto: Colleges Ontario, 2018).

16. Michael Skolnik, "Quality Assurance in Higher Education as a Political Process," Higher Education Management and Policy, 22:1 (2010), 1-20.

17. Ontario College Quality Assurance Service (OCQAS), "About," OCQAS (Toronto: OCQAS, 2016a), Retrieved from https://www.ocqas.org/ about/ (accessed 1 August 2019).

18. Ontario College Quality Assurance Service (OCQAS), College Quality Assurance Accreditation Process: Guidelines and Framework (Toronto: OCQAS, May 2019).

19. Ibid.

20. National Indigenous Accreditation Board (NIAB), Accreditation Handbook, 4th Edition (Edmonton, Alberta: NIAB, 2016), http://niab-accreditation. com/accreditation-manual.html (accessed 1 August 2019)

21. Nā Lau Lama Culture-Based Education Working Group, Nā Lau Lama Culture-Based Education Working Group: Preliminary Working Group Findings (n.d.), http://www.ksbe.edu/_assets/spi/ pdfs/reports/na-lau-lama/NLL-CBE-pre-findings. pdf.

22. Alaska Native Knowledge Network (ANKN), Alaska Standards for Culturally-Responsive Schools (Fairbanks: University of Alaska Fairbanks, 1998), 3.

23. World Indigenous Nations Higher Education Consortium (WINHEC), WINHEC (n.d.), winhec.org/ about-winhec/ (accessed 1 August 2019).

24. Manulani Meyer, "Remembering Our Future: Higher Education Quality Assurance and Indigenous Epistemology," World Indigenous Nations Higher Education Consortium Journal (2005), 2005,1827. 
25. World Indigenous Nations Higher Education Consortium Accreditation Authority, WINHEC Accreditation Handbook: Higher Education, 3rd Edition. (Honolulu, Hawai'i: WINHEC, 2010).

26. WINHEC Accreditation Authority, WINHEC Accreditation Handbook.

27. Ibid.

28. National Indigenous Accreditation Board (NIAB), National Indigenous Accreditation Board (Edmonton, Alberta: NIAB, n.d.), http://www niabaccreditation.com/welcome.html (accessed 1 August 2019).

29. NIAB, Accreditation Handbook.

30. Ibid.

31. Skolnik, "Quality Assurance in Higher Education."

32. Meyer, "Remembering our Future."

33. Ibid.

34. Ontario College Quality Assurance Service (OCQAS), Final Audit Report Executive Summary: Sault College May 2014 (Toronto: OCQAS, 2014).

35. Ontario College Quality Assurance Service (OCQAS), Northern College: Executive Summary of Final Audit Report (Toronto: OCQAS, 2016b).

36. WINHEC, WINHEC.

37. Diane Longboat, First Nation Education Law Template for First Nation Governments, [webinar presentation] (Naughton: Ontario Native Education Counselling Association, 2013), https://www.afn. ca/uploads/files/usb2013/2-d.pdf (accessed 1 August 2019).

38. Ranginui Walker, "Quality Assurance in Tertiary Education from a Māori (Indigenous) Perspective," Tihei Oreore, 1:1 (2005), 143.

39. James Jacob et al., "An Organisational Analysis of the World Indigenous Nations Higher Education Consortium," World Indigenous Nations Higher Education Consortium (WINHEC) Journal (2013), 40-52.

40. Jerald Paquette, and Gerald Fallon, "In Quest of Indigeneity, Quality, and Credibility in Aboriginal Post-Secondary Education in Canada: Problematic, Contexts, and Potential Way Forward," Canadian Journal of Educational Administration and Policy, 165 October (2014).

41. Peter Hodson, and Harold Thomas, "Higher Education as an International Commodity: Ensuring Quality in Partnerships," Assessment and Evaluation in Higher Education, 26:2 (2001), 101-112.

42. Ibid, 107.
43. Hanover Research, Program Quality Assurance Best Practices (Washington DC: Hanover Research, 2010).

44. Nick Zepke, and Linda Leach, "Educational Quality, Institutional Accountability and the Retention Discourse," Quality in Higher Education, 13:3 (2007), 237-248.

45. Mary Wabano, Healing and Wellness and the Role of Community Colleges: A Formative Program Evaluation (Master's Thesis, Ottawa: University of Carleton, 2014), 45.

46. Raven Sinclair, "Participatory Action Research and Aboriginal Epistemology," Teaching \& Learning, 4:2 (2007), 28.

47. Kevin Walby, "Institutional Ethnography and Surveillance Studies: An Outline for Inquiry," Surveillance \& Society, 3:2/3 (2005), 158-172.

48. Dorothy Smith, The Everyday World as Problematic: A Feminist Sociology (Toronto: University of Toronto Press, 1987).

49. Gaudry and Lorenz, "Indigenization as Inclusion, Reconciliation, and Decolonization," 222.

50. Daigle, "The Spectacle of Reconciliation," 8.

51. Ibid, 8.

52. Pidgeon, "More Than a Checklist."

53. Gaudry and Lorenz, "Indigenization as Inclusion, Reconciliation, and Decolonization," 218-19.

54. Daigle, "The Spectacle of Reconciliation," 3.

55. Pidgeon, "More Than a Checklist."

56. Pidgeon, "More Than a Checklist."

57. Michelle Pidgeon, "Moving Beyond Good Intentions: Indigenizing Higher Education in British Columbia Universities through Institutional Responsibility and Accountability," Journal of American Indian Education, 53:2 (2014), 7-28.

58. Pidgeon, "More Than a Checklist."

59. Daigle, "The Spectacle of Reconciliation," 2.

60. Ibid, 5.

61. Marie Battiste, Indigenous Knowledge and Pedagogy in First Nations Education: A Literature Review with Recommendations (Ottawa: Indian and Northern Affairs Canada (INAC), 2002), 29.

62. Aman Sium, Chandni Desai, and Eric Ritskes, “Towards the 'Tangible Unknown': Decolonization and the Indigenous Future," Decolonization: Indigeneity, Education \& Society, 1:1 (2012), I-XIII.

63. Episkenew, “Indigenizing University Administration or Tâwaw cî? (Take 2)."

64. Pidgeon, "More Than a Checklist." 
